\title{
ORAN, UNE VILLE DE FORTIFICATIONS
}

Par Metair Kouider,

Président de l'association de protection du patrimoine oranais Bel Horizon de la ville d'Oran

Avec près d'un trentaine de fortifications, Oran fut l'une des villes les plus fortifiées de la Méditerranée, ce qui fera dire à un observateur, frappé par le nombre et la taille des fortifications oranaises : «On est étonné de la grandeur de ces constructions pour une si petite enclave». Ces fortifications sont l'œuvre de près de trois siècles (de 1505 à 1792) d'occupation espagnole des villes de Mers El kébir et d'Oran.

\section{1-UN PEU D'HISTOIRE}

La ville d'Oran, fut fondée en l'an 902 par des marins andalous de Cordoue. Ils installèrent un comptoir commercial dans la fabuleuse baie de Mers el Kébir, connue depuis l'antiquité et que les Romains baptisèrent à juste titre Portus Divini. Une baie profonde et bien protégé et qui présente un excellent mouillage.

La petite cité prospère et attire les convoitises des pouvoirs et dynasties de la région du Maghreb et plus tard de l'Europe et de l'empire ottoman. C'est ainsi qu'Oran, fut successivement durant six siècles une cité musulmane et tour à tour: omeyyade, fatimide, almoravide, almohade, mérinide et zianide, pour tomber ensuite entre les mains des espagnols, des ottomans et enfin des français jusqu'en 1962. Souvent conquise mais jamais soumise dirait le poète!

Après la chute de Grenade, Oran recevra de plein fouet les effets de la Reconquista.

L'immense rade de Mers El Kabîr est occupée en 1505 par don Diego de Cordoba. Quatre ans plus tard, Oran tombe entre les mains du cardinal Ximenes, archevêque de Tolède et confident d'Isabelle la Catholique, qui, dans son testament, incitera ses successeurs à poursuivre l'œuvre de la Reconquista, par la conquête des 
villes musulmanes d'Afrique du Nord. Le fidèle et fébrile archevềque financera l'expédition d'Oran et participera avec les troupes de Pedro Navarro à la prise de la ville. Ximenes présentera au roi cette conquête comme une grosse prise, la comparant à l'enlèvement de Jérusalem par les croisés en 1099. Il fit donc un rapport élogieux sur la ville et ses richesses et ordonna l'exécution d'une grande fresque décorative au sein même de la cathédrale de Tolède pour immortaliser l'événement.

Par la suite, les Espagnols réussirent à prendre Tlemcen, capitale du royaume des Zianides. L'arrivée des Ottomans, à partir de 1516, va sérieusement contrarier les ambitions espagnoles. La ville de Tlemcen changera de mains plusieurs fois selon un rapport des forces qui dictait aux rois locaux leur allégeance. C'est au Comte D'Alcaudete qu'échoit la mission de garder Tlemcen et de conquérir Mostaganem. D'ailleurs, il portait bien le titre de «Capitaine Général du royaume de Tlemcen et de Ténès et gouverneur des Places d'Oran et de Mers El Kébir».

Durant les 24 années de son règne à Oran, les batailles aux alentours ne cessèrent à aucun moment, jusqu'à la débâcle de Mostaganem en 1558, où le chef espagnol perdit la totalité de ses troupes et y laissa sa vie.

Ainsi tirant les conclusions de leurs déboires «tlemceniens et mostaganemois», et ne pouvant pénétrer durablement l'arrière-pays, après plusieurs tentatives en direction des villes de Tlemcen et Mostaganem, les Espagnols décident de transformer Oran en un «presidio» majeur et lancent un vaste et ambitieux programme de fortifications.

Les travaux de fortification à Oran ont connu deux grandes périodes : Celles de 1505 à 1708 , ensuite de 1732 à 1792 , correspondant à la $1^{\text {ère }}$ et à la $2^{\text {ème }}$ occupation

La première période a vu s'effectuer l'essentiel des travaux, la deuxième celle du confortement, de l'amélioration et la construction de nouvelles fortifications, suite aux leçons tirées après la perte de la ville en 1708, et sa conquête par l'audacieux Bey Mustapha Ben Youssef el Mesrati dit Bouchelaghem, et appelé «El Bigotillos» en espagnol en référence à ses généreuses moustaches. C'est le Commandant Général titulaire d'Oran, Don José Vallejo, qui s'illustra particulièrement lors de cette deuxième période, par d'ingénieux aménagements et de multiples travaux de confortement et d'agrandissement des fortifications. Il fit construire d'autres forts comme le San Fernando et San Carlos et améliorera les fortifications de San Felipe, Santa Cruz, Santiago, Santa Barbara, etc. 
Ce complexe système de fortifications permettra aux espagnols de résister à de terribles et longs sièges et de garder la ville durant près de trois siècles.

Oran sera définitivement libérée par les armées algéro-otomanes en 1792. Mais la longue et singulière présence espagnole aura laissé des vestiges importants que l'on peut observer encore de nos jours. Un patrimoine partagé d'une richesse exceptionnelle, œuvre des meilleurs ingénieurs et architectes de l'époque comme Juan Bautista Calvi et Saluago ainsi que Bartolomé Quémado de Gibraltar et enfin de Batista Antonnelli, le préféré de Philipe II

\section{2- LES PREMIÈRES FORTIFICATIONS}

Oran était une ville fortifiée bien avant l'occupation espagnole. En effet, le fort de Mers El kébir était déjà construit du temps des Mérinides, ainsi que probablement les Donjons et ce vers 1347 (Fig. 1). Léon l'africain donnait cette description de la cité juste avant l'occupation espagnole.: «Oran est une grande cité bien fournie d'édifices et de toutes choses qui sont séantes à une bonne cité, comme collèges, hôpitaux, bains publics et hôtellerie, la ville étant ceinte par ailleurs de belles et hautes murailles.»

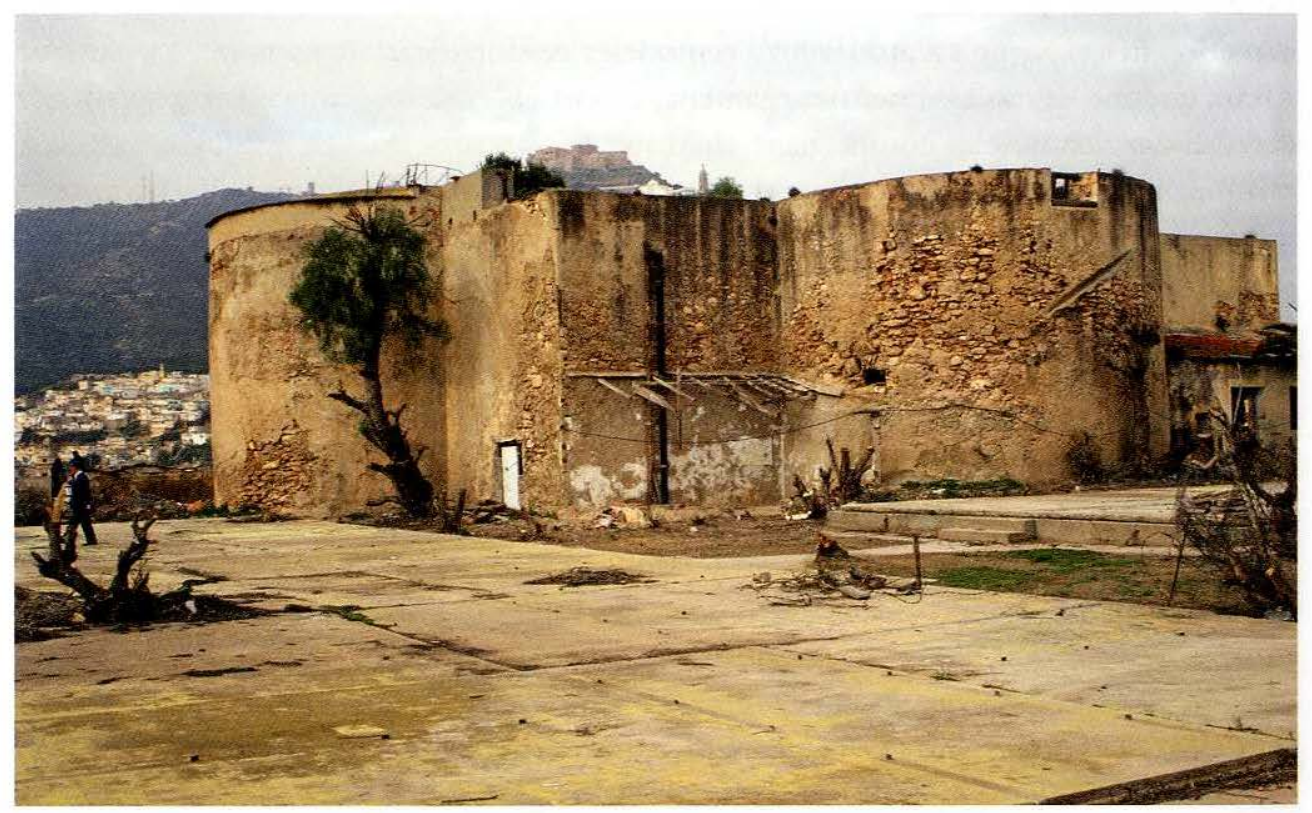

Fig. 1. Les Donjons mérinides 1374. 


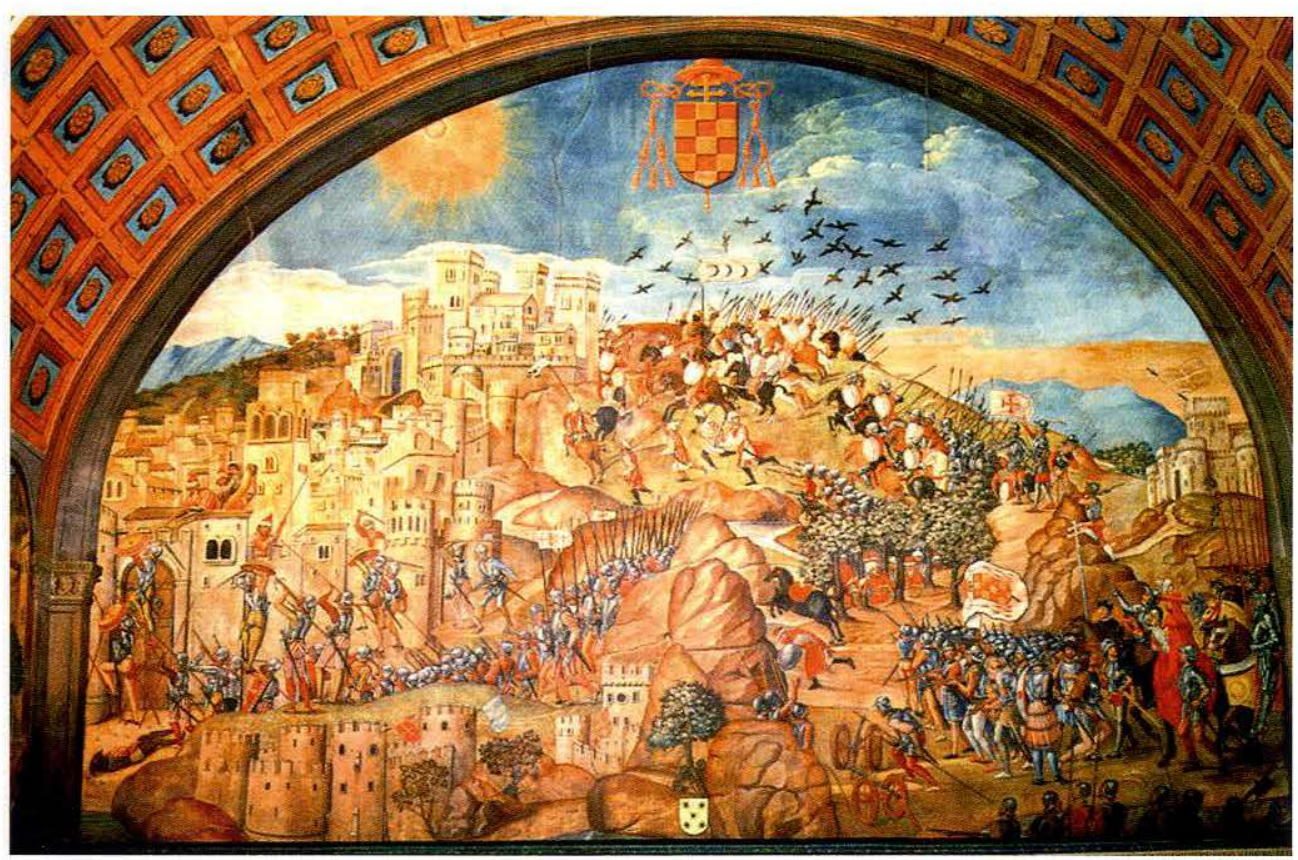

2. Fresque sur la prise d'Oran par les espagnols.

Les espagnols s'attelèrent à remodeler ces fortifications et murailles par leur confortement, agrandissement et réaménagement et leur intégration dans un système défensif fort complexe comprenant châteaux forts, forts, fortins, réduits, bastions, ravelins, murailles ainsi que mines et galeries souterraines. Un joyau de l'architecture militaire de l'époque! (Figs. 2, 3 y 4).

\section{2-1 Les châteaux forts:}

Le système de fortifications comprenait une cité fortifiée protégée par deux lignes: les fortifications de l'est et de l'ouest du ravin de Raz el Aïn, là ou coulait la principale source d'eau douce et ou se trouvait les jardins potagers vitales pour la ville. Le tout complété par les fortifications de protection du port de Mers el Kébir et de l'anse d'Oran.

Oran comprenait, outre les fortins et murailles bastionnées, six (6) châteaux forts : Mers El kébir, Santa Cruz, Saint Grégoire, Rosalcazar, Saint André et Saint Philipe, dont nous allons décrire les plus intéressants: 

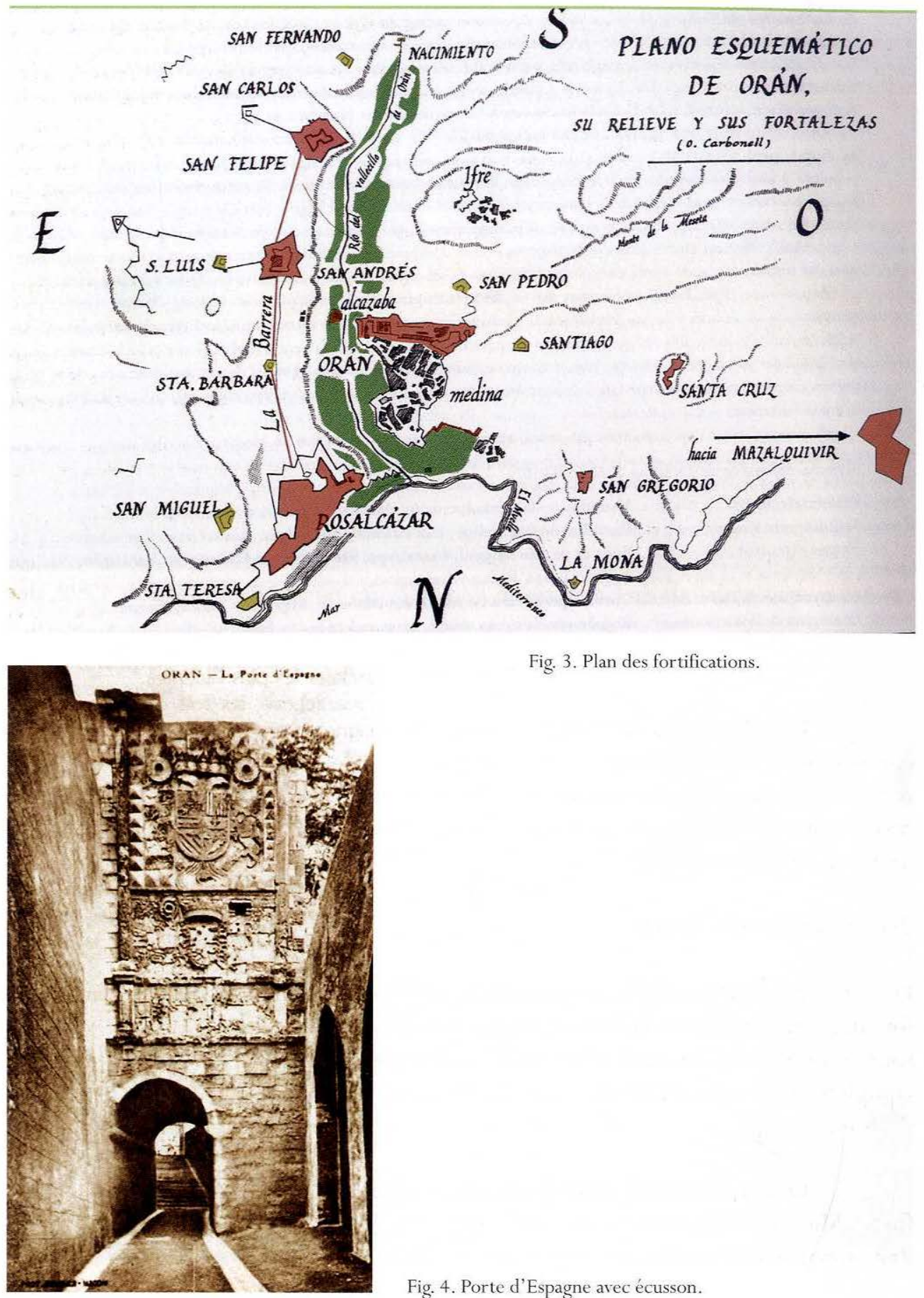

Fig. 3. Plan des fortifications.

Fig. 4. Porte d'Espagne avec écusson. 


\section{- Mers El Kébir (Fig. 5 y 6):}

Les Mérinides, venus de Fès, construirent en 1347, une première fortification carrée avec une tour, sur le promontoire qui ferme la baie de Mers El Kébir sur le flanc ouest. Il constitua alors le verrou du grand port, impossible à miner, car prenant la forme de la langue de terre qui se jette dans la mer. Au sud, il est protégé par un ravelin à tenaille double, flanqué de deux bastions et séparé de la fortification par un fossé. Le tout est dominé par la montagne du Santon, que coiffe une fortification dite de San Salvador. Le fort de Mers el Kébir constitue la plus belle fortification d'Oran, avec de hautes murailles crénelées, ponctuées de bastions et de tours de garde. Elle disposait de neuf grandes bâches d'eau, alimentées par les eaux de pluie. Elle pouvait abriter une garnison de plus de 500 hommes et jusqu'à 3000 en temps de guerre, et possédait plus de 50 canons en bronze et en fer. Mers el Kebir a connu de très grandes batailles et a résisté aux plus grands assauts et autres sièges. C'est une fortification qui s'est avérée imprenable lors du terrible siège de Hassan Pacha en 1563. Siège qui inspira Cervantès dans son vaillant espagnol (El gallardo español). De par sa situation, Mers el Kébîr fut l'ultime possibilité de retraite comme ce fut le cas en 1708. C'est la porte d'accès et de sortie pour tout conquérant venant de la mer, comme ce fut le cas des marins andalous de Cordoue en l'an 902, des espagnols en 1505 et 1792, des

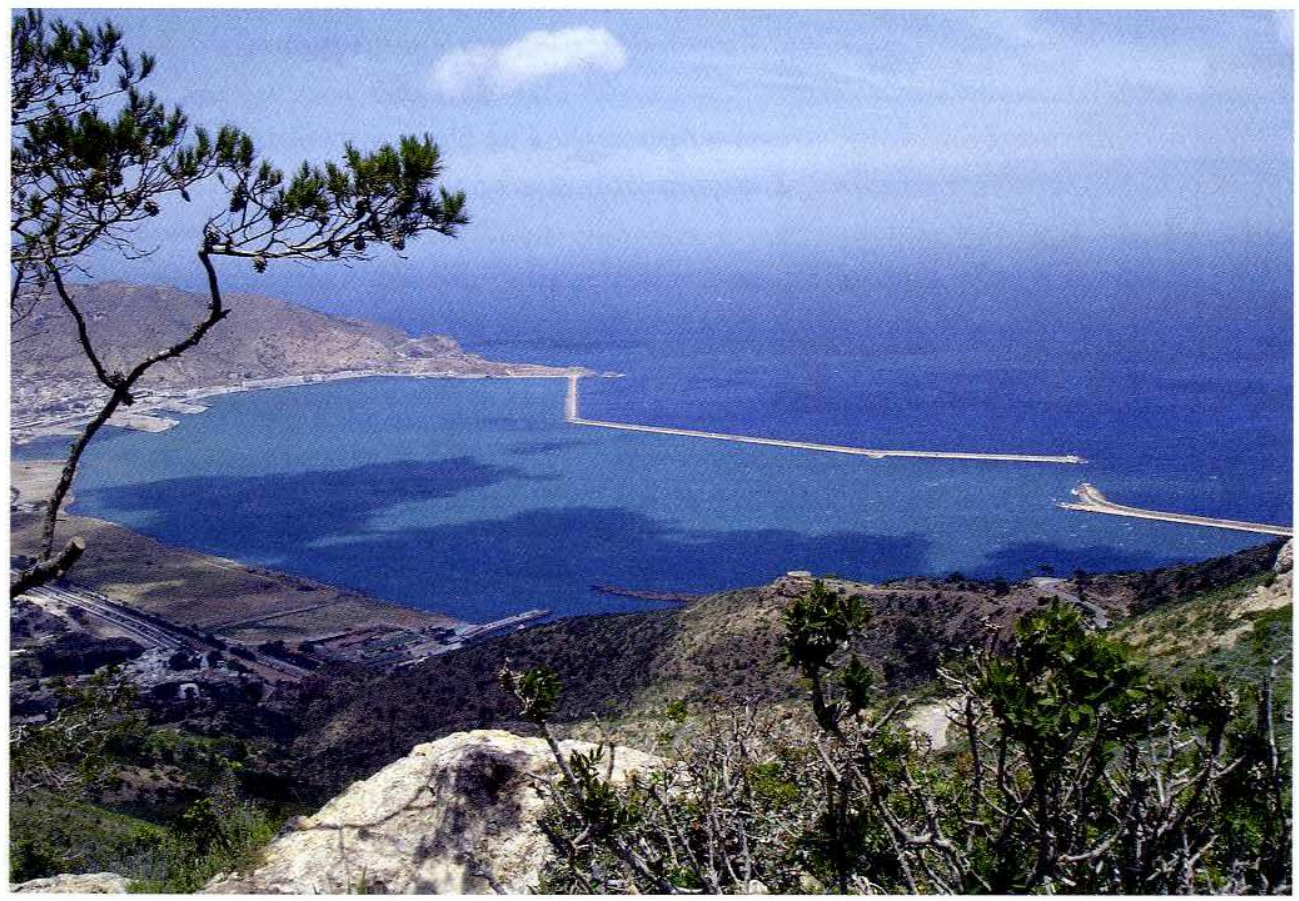

5. La baie de Mers El Kébir. 


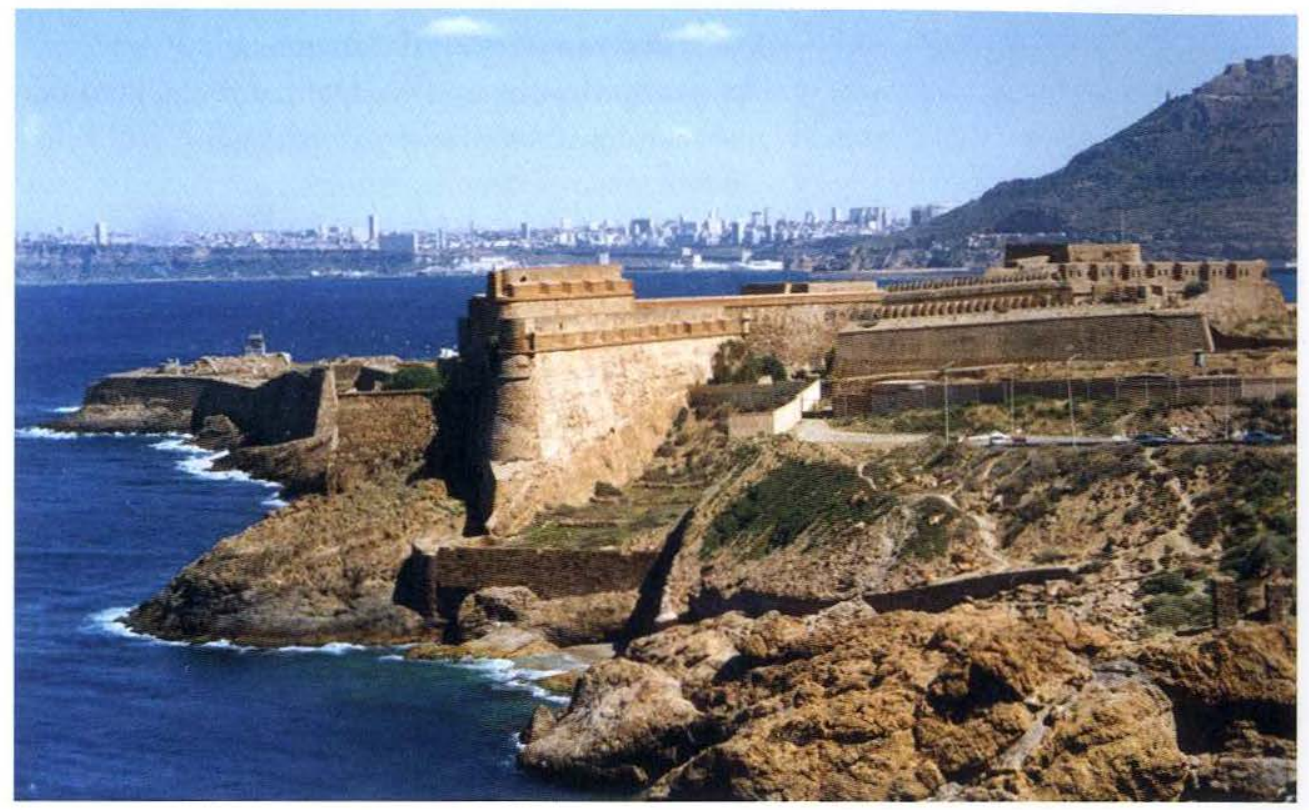

6. Le fort de Mers El Kébir.

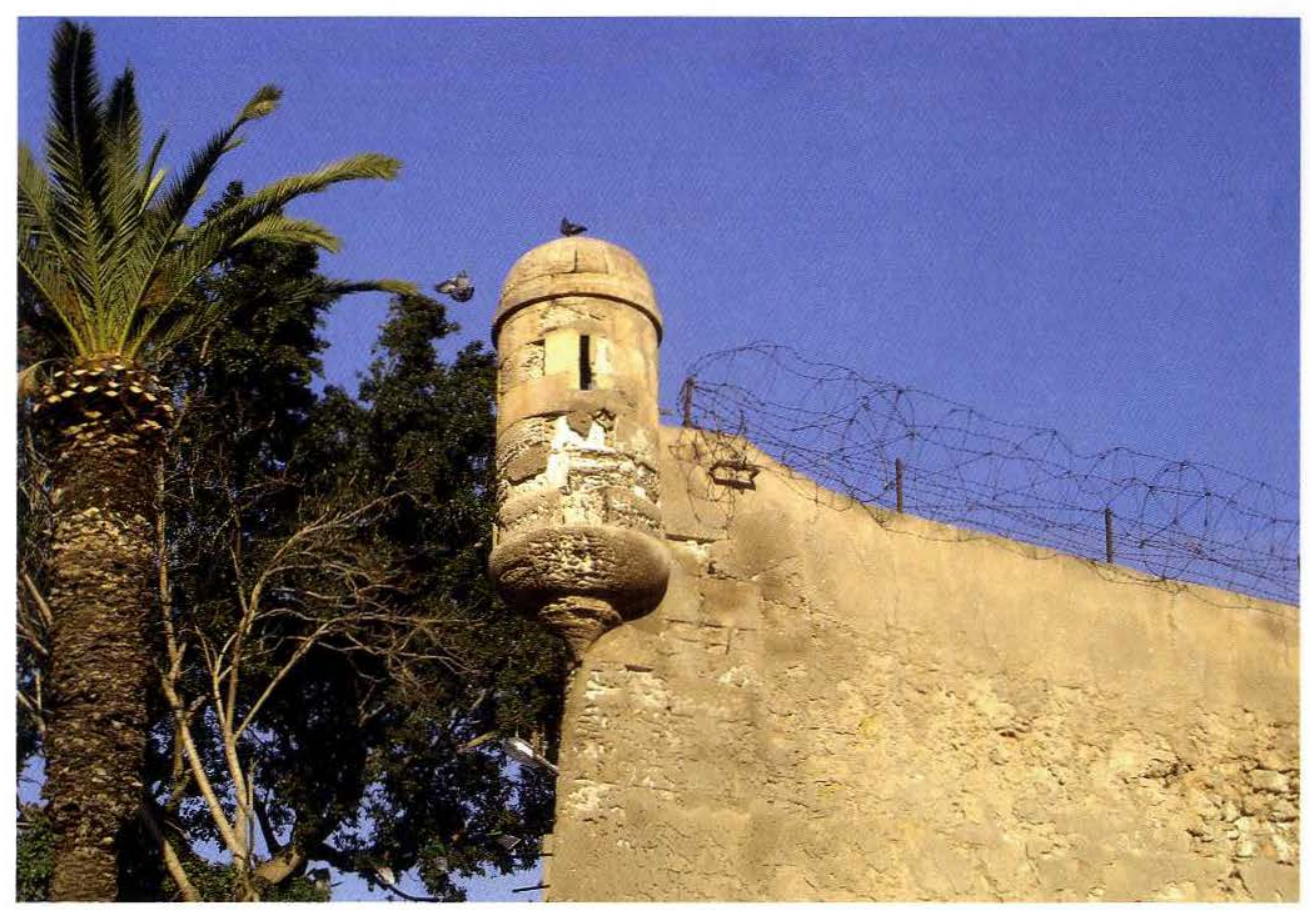

7. Echauguette. 
français en 1830 et en 1962; La rade a servi aussi de point d'attáque à la Royal Navy en 1940 contre la flotte française et de point d'appui au débarquement américain de 1942

Dans les années 1950, la fortification abritait annuellement un festival du théâtre classique et des spectacles de sons et lumières. Actuellement la fortification est intégrée à la base militaire de la marine de Mers el kébir.

\section{- Le fort de Santa Cruz:}

Situé sur le sommet d'une montagne, à $375 \mathrm{~m}$ d'altitude, il surplombe à la fois la ville et le port de Mers El kébir. Une silhouette impressionnante, posée sur un nid d'aigle avec un tracé irrégulier pour s'adapter aux sinuosités du terrain. Albert Camus n'en pensait pas moins: «on dirait que cette fortification n'a pas été construite, mais plutôt taillé dans le roc, tellement la roche vive se mariant admirablement avec la pierre de taille» (Fig. 8 y 9).

Santa Cruz protège le fort Saint Grégoire, qui lui-même défend le fort Lamoune et l'accès au port.

Il parait inexpugnable mais n'a pas résisté à l'assaut du Bey Bouchlaghem en 1708 .

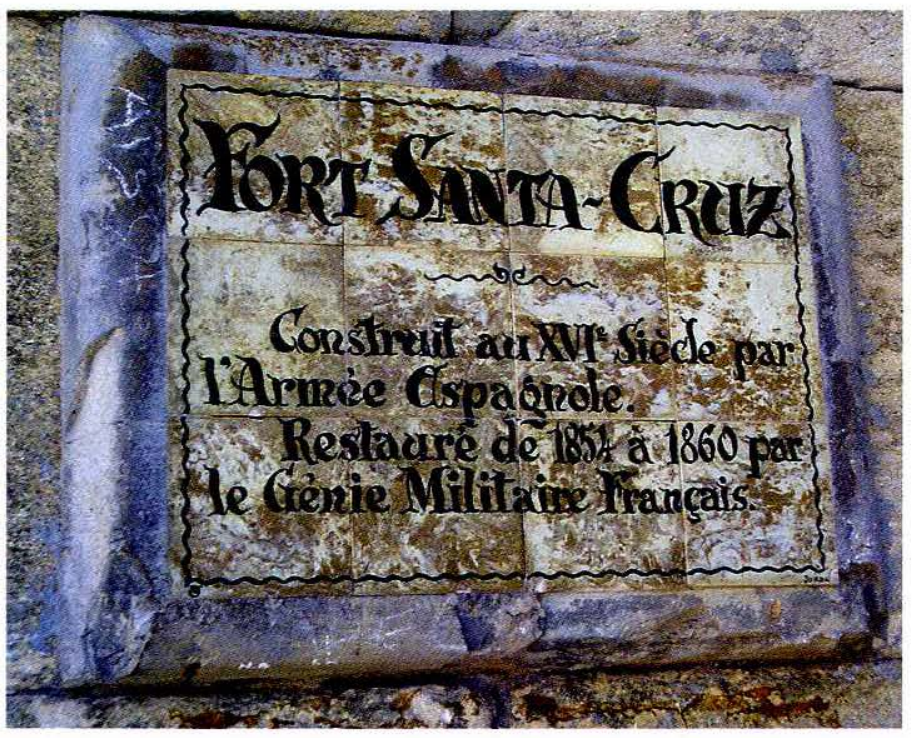

8. Inscription à l'entrée du fort Santa Cruz.
En cette année, les troupes algéroottomanes le harcelèrent par des bombardements du haut de la montagne du Murdjajo, à $410 \mathrm{~m}$ d'altitude. A la faveur des bombardements, des mineurs s'approchèrent de la base des murailles et créèrent une brèche à l'explosif, par laquelle s'engouffrèrent les assaillants, prenant relativement facilement le fort, puis les autres fortifications. La ville, 
dégarnie de sa défense, tomba comme un fruit mûr. Quand en 1732, les troupes espagnoles reprennent la ville, Don Vallejo, alors gouverneur, tira toutes les leçons relatives aux faiblesses présentées par la fortification lors de l'assaut de 1708. C'est ainsi qu'il ajouta un petit ouvrage à cornes, sur le flanc sud-ouest dit ravelin de la brèche, bien maçonné, pour pouvoir subir sans gros dégâts et amortir les bombardements provenant des hauteurs d'en face. Il provoqua ensuite une séparation physique avec le plateau de la montagne en accentuant la dépression naturelle et en opérant une profonde entaille. Le fossé sera amélioré et précédé d'une falaise à l'arête bien raide qu'un assaillant ne peut l'emprunter sans risque de chuter inévitablement. Les murailles sont renforcées et prennent racine dans le roc en collant à la verticale de la falaise. Les échauguettes, érigées sur les bastions et munies de mâchicoulis ; complètent le dispositif défensif et

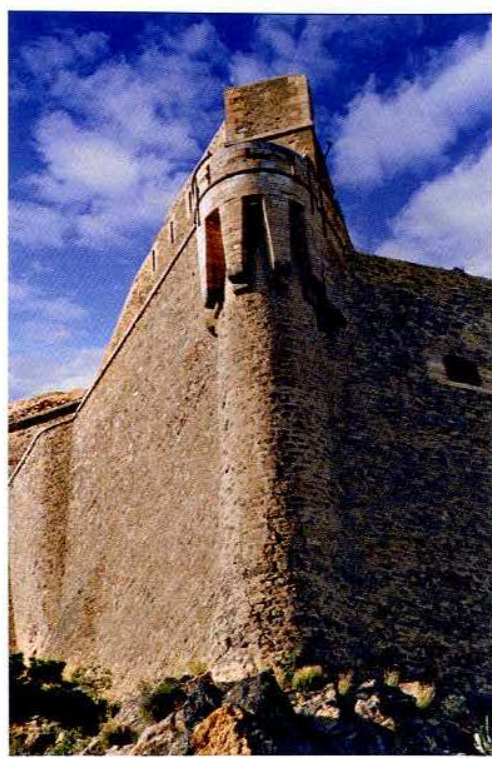

9. Echauguette fort Santa Cruz. concourent à faire du fort Santa Cruz une fortification redoutable. D'autres travaux vont donner une allure particulière à sa beauté austère. Les murailles, les abris, les voûtes, les angles, les escaliers sont en pierre de taille appareillés et bien maçonnés. L'autonomie en eau est assurée par plusieurs citernes enterrées et alimentées par un système de récupération des eaux de pluie.

Le fort fut ruiné et désarmé en 1792, après le départ des troupes espagnoles. Il fut restauré en 1865 par le «génie militaire français» comme l'indique une plaque apposée à l'entrée. Les français introduirent quelques modifications comme le déplacement de la citerne, l'amélioration du système de captation d'eau et le rajout de quelques infrastructures.

A quelques mètres au dessous du château, à côté de la chapelle, on rencontre les ruines de la redoute de Santa-Cruz, qui était un poste avancé de la forteresse.

Santa Cruz pouvait abriter jusqu'à 500 hommes et disposait de plus de 30 canons.

Actuellement, le fort est en chantier de restauration après avoir été évacué par les militaires. Il sera transformé en Musée du Vieil Oran, réunissant côte à côte splendeur architecturale et vue panoramique et mariant avec brio art et nature (Fig. 10 a 16). 


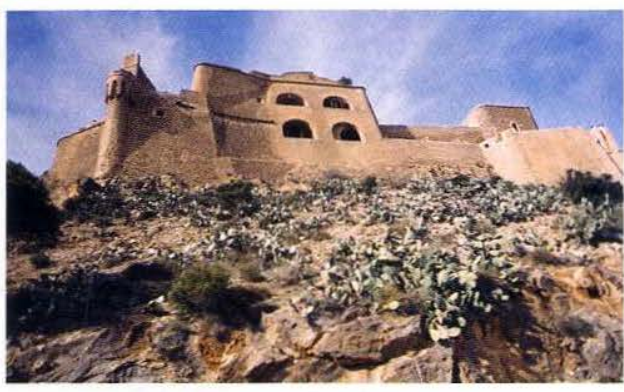

10. Fort Santa Cruz.

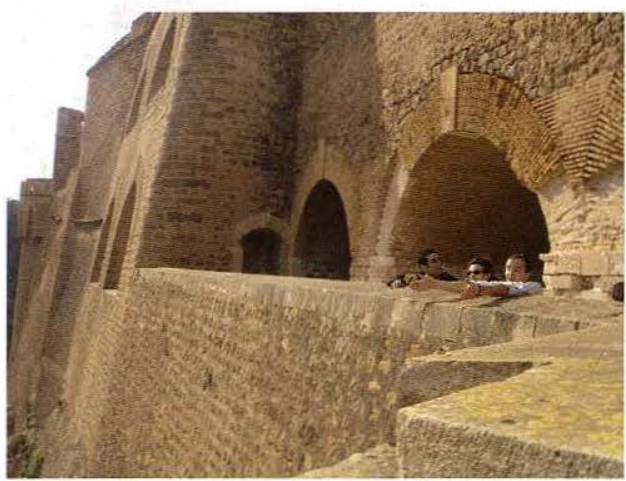

12. Le bastion Est du F. Santa Cruz.

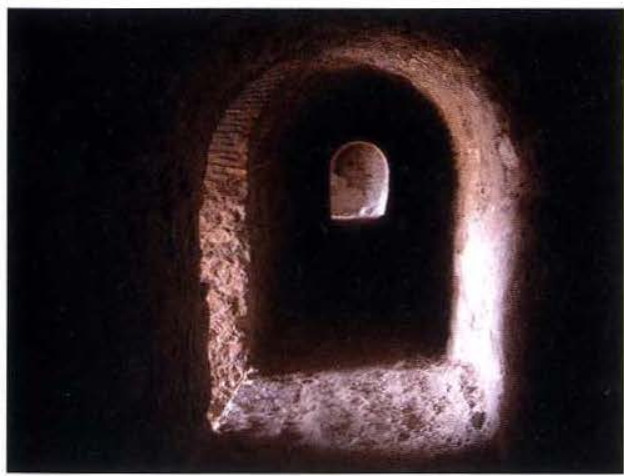

14. Galierie au F. Santa Cruz.

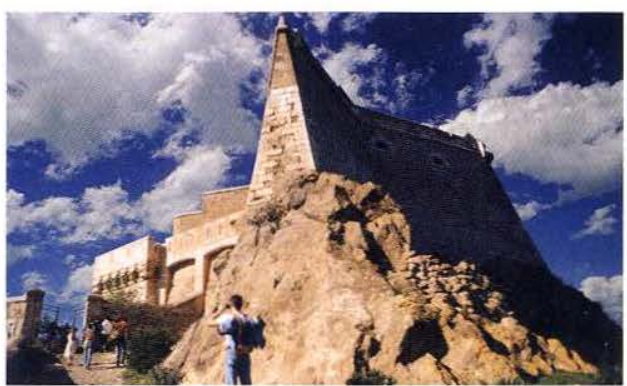

11. Les voutes de Santa Cruz.

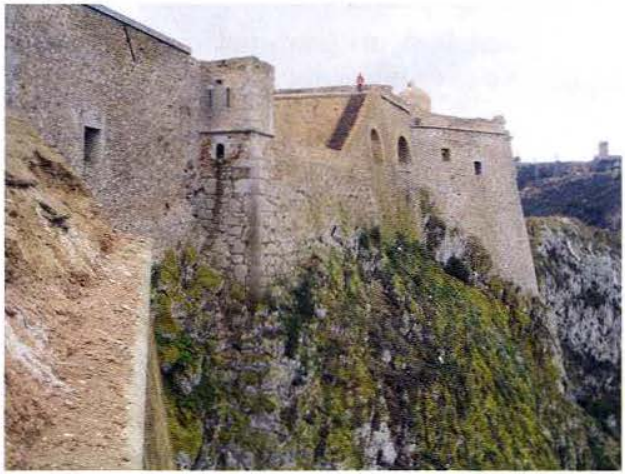

13. Le flanc Nord du fort Santa Cruz.

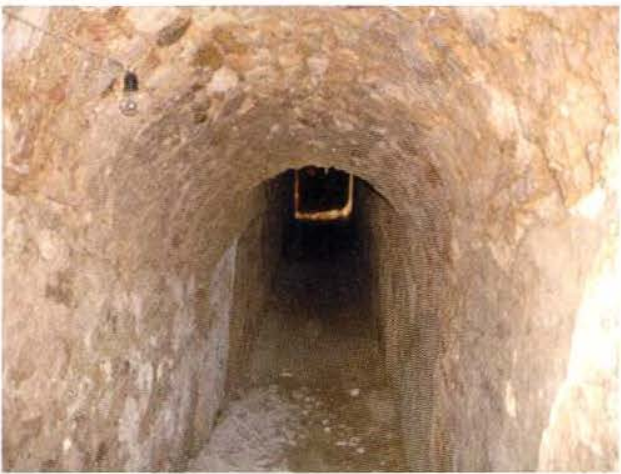

15. Galierie au sein du fort Santa Cruz. 


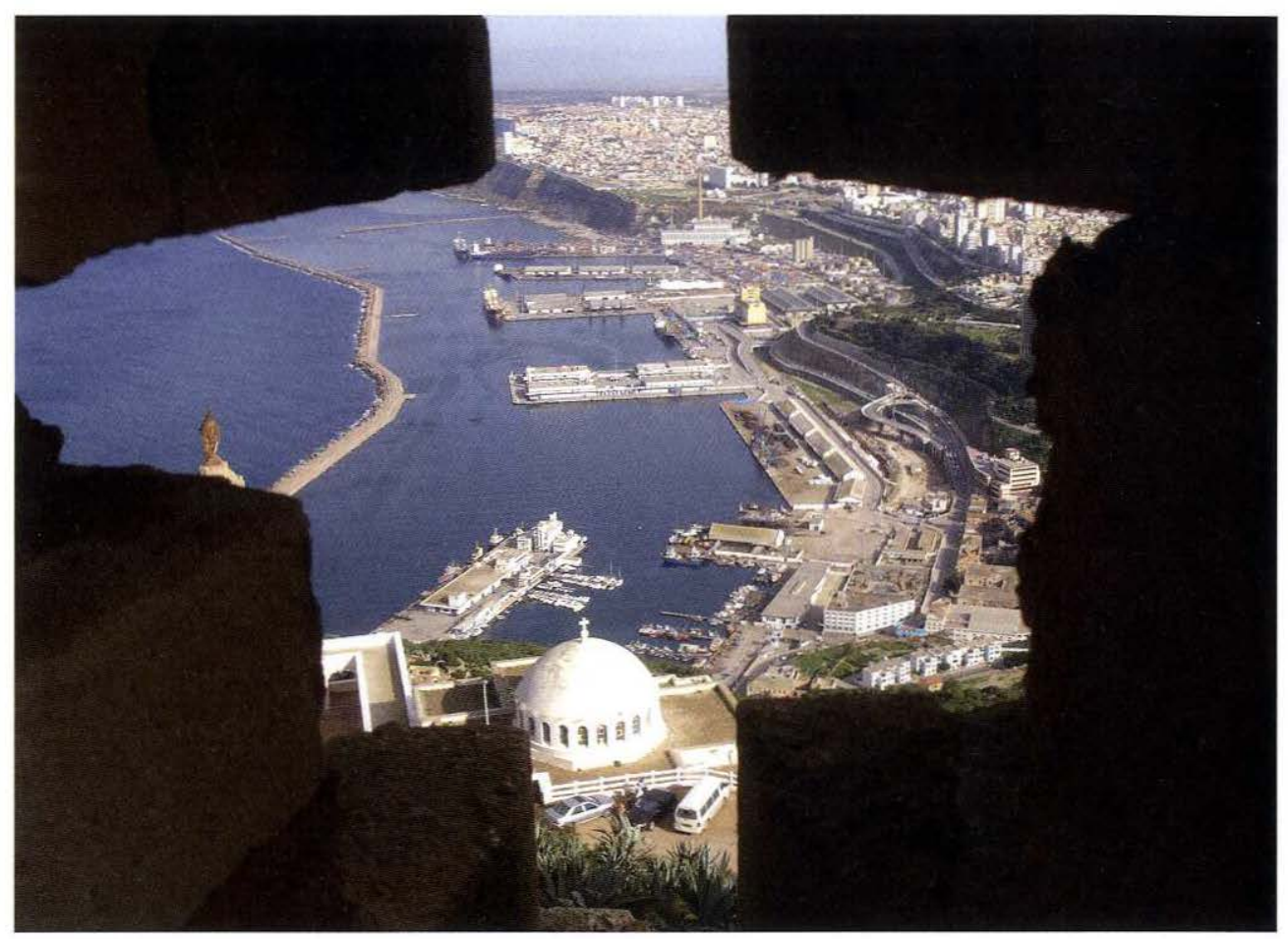

16. Vue d'Orán d'une meurtrière de Santa Cruz..

\section{- Fort San Grégoire:}

C'est le seul château fort aujourd'hui complètement disparu. Il a été ruiné par l'armée française au début du XX ${ }^{\text {eme }}$ siècle. Seuls subsistent quelques remparts et bâtisses et des voûtes creus\&es dans le roc.

Situé à 175 m en dessous de Santa Cruz, il est formé d'une étoile irrégulière.

Déjà au temps des Espagnols, il était question de le démolir pour en faire une batterie circulaire en forme de fer à cheval.

Il tient sous ses feux la marine, la route de Mers el kebir et défend le chemin vers Santa Cruz.

- Le Rosalacazar ou Bordj el Ahmar (Fig. 17):

«Le Rosalcazar est le meilleur de tous les châteaux forts d'Oran ; ses dimensions régulières et ses fortifications solides le rendent imprenable et je doute même 


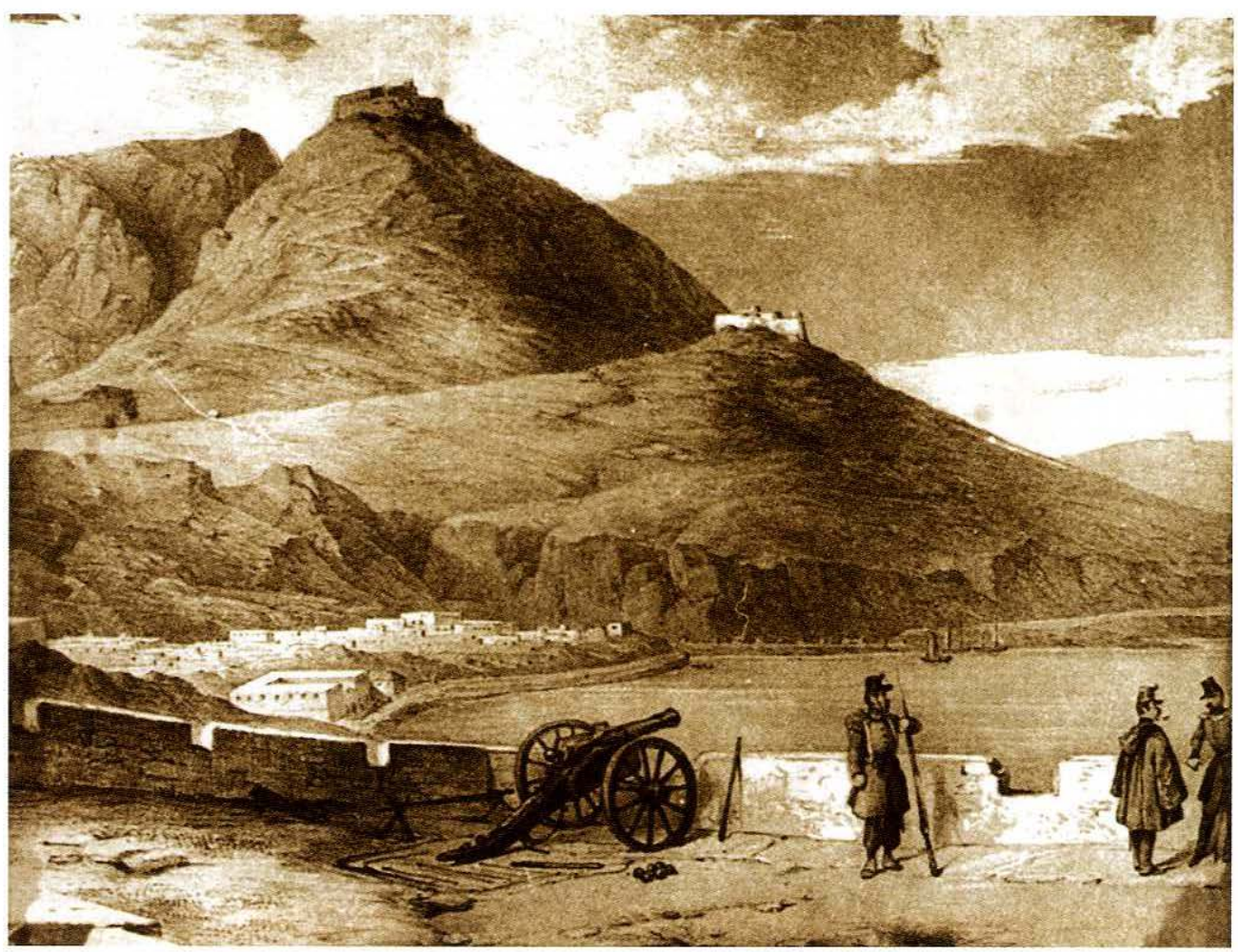

17. Le Rozalcasar.

qu'on en trouve de plus beau dans une nation européenne», c'est ainsi que le décrivait le Commandant Général de la Place d'Oran, Don José Vallejo, dans son rapport, rédigé en 1734, sur «L'état et la valeur des Places d'Oran et de Mers El kébir», adressé au roi d'Espagne. Bien avant les espagnols, les mérinidas avaient compris le caractère stratégique du promontoire et ont été les premiers à jeter les fondements de la future fortification, notamment par la construction des Donjons. Cette fortification a impressionné plus d'un voyageur. Comme ce poète historien décrivant Bordj el Ahmar, nom arabe du Rosalcazar: «le Bordj el Ahmar est la réunion de ce que l'art a produit de plus surprenant».

S'étalant sur plus de sept hectares et déroulant une muraille de plus de deux mille mètres, le Rosalcazar fut et demeure la plus grande fortification oranaise (Figs. 18-19).

La fortification, située à l'est et au dessus de la ville, est protégée des deux côtés par de larges ravins. Elle est exposée aux attaques du côté du sud ouest. La dé- 


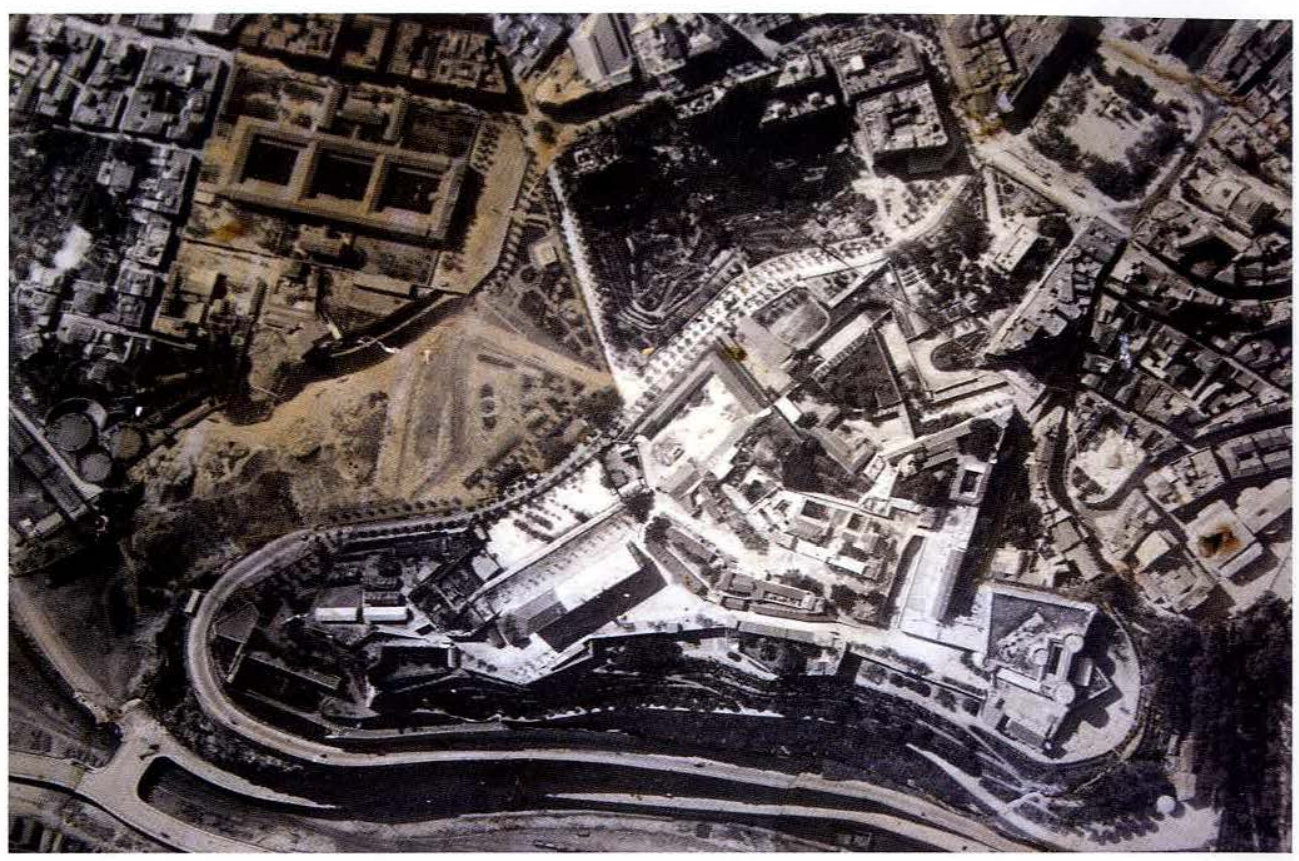

18. Le Rozalcasar.

fense est renforcée, à ce niveau là, par une double tenaille et un large et profond fossé de $20 \mathrm{~m}$ de large et $250 \mathrm{~m}$ de longueur. Ses larges courtines à parapet sont ponctuées de manière irrégulière. Au nord est, du coté de la plage, la défense est assurée par la lunette Santa Teresa, aujourd'hui disparue.

Le glacis et le bastion principal sont bien visibles et servent de prolongement à la place principale du centre ville. Les courtines, couronnées de parapet, sont flanquées de manière irrégulière de demi bastions, coiffés de jolies échauguettes à mâchicoulis. A l'intérieur de la fortification, sur la pointe sud, le Bey Ottoman Mohamed El Kébir fit construire un palais en 1792, soit l'année de l'évacuation définitive par l'armée espagnole de la ville. Il érige un joli pavillon sur le redoutable bastion sud, dont la forme de proue lui donne une allure redoutable de cuirassé.

A l'intérieur sont visibles la poudrière, les tunnels de communications avec les réduits et autres fortins extérieurs. On y trouvait évidemment une grande citerne.

La fortification dispose d'une seule porte d'entrée. Monumentale et bien ouvragée, protégée à sa droite par le bastion dit des Maltais, qui ceinture les 


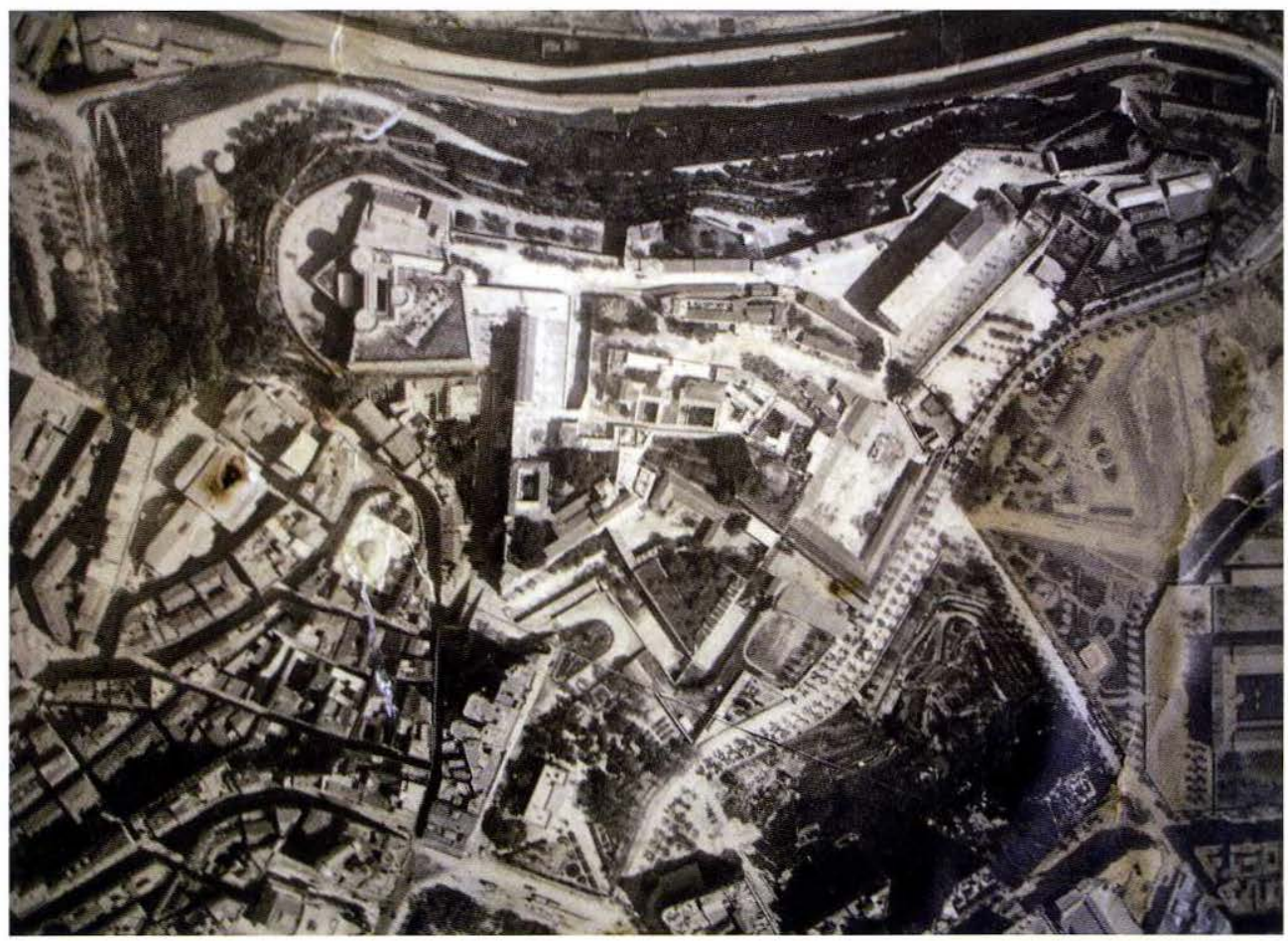

19. Le Rozalcasar.

donjons, elle porte deux inscriptions, l'une espagnole, illisible actuellement mais qui faisait référence à la construction des voûtes et de la porte du temps de Charles III en l'année 1760 sous le commandant de la place Don Juan Martin Zermeño. L'autre inscription en arabe relate la prise d'Oran par le bey Mohamed el Kebir, en 1792.

Sur la muraille sud fut sculpté un écusson, dédié au roi Phillipe $\mathrm{V}$, avec une inscription en espagnol donnant la date de 1701, comme fin des travaux.

Il reçu la visite de Don Juan d'Autriche, frère du roi en 1568, qui fut frappé par son promontoire

Actuellement, les murailles et les échauguettes sont en bon état ainsi que le porte d'entrée et les splendides voûtes au nombre de dix. Un projet de restauration du système défensif, ainsi que les donjons va être incessamment lancée. Une carcasse en béton de 17 étages a été malheureusement érigée en plein centre de la fortification 
et qui devait servir d'hôtel. A défaut de la raser, on lui a dernièrement changé de vocation, pour servir d'hôtel de ville (mairie).

\section{- Saint Philipe, ou château des Saints:}

Il est situé dans le prolongement de Saint André et du Rosalcazar. Il ferme et défend la rive droite du ravin de Ras El Aïn, où coule le principal cours d'eau de la ville d'Oran.

Stratégique puisqu'il domine le ravin et les pentes de la montagne du Murdjajo, et il est assez élevé pour battre la rase campagne jusqu'aux alentours du Rosalcazar.

Actuellement caserne militaire, seules les murailles d'enceinte et les murs de soutènement demeurent visibles de loin et rendent compte de l'importance qu'il avait.

Les galeries de communication avec San Carlos, rasé pour les besoins de l'urbanisation du quartier de Saint Antoine, demeurent toujours fonctionnelles comme abris (Figs. 20-21).

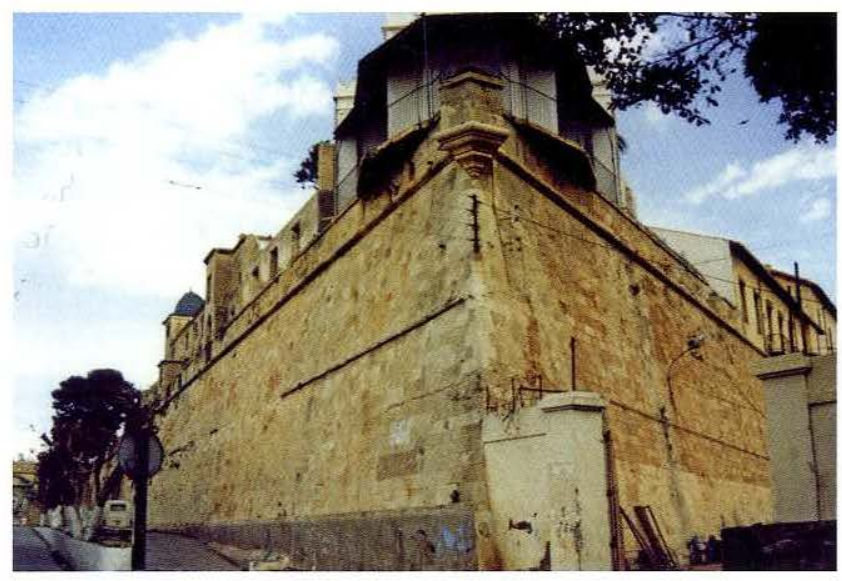

20. Le bastion au Castillo Viejo.

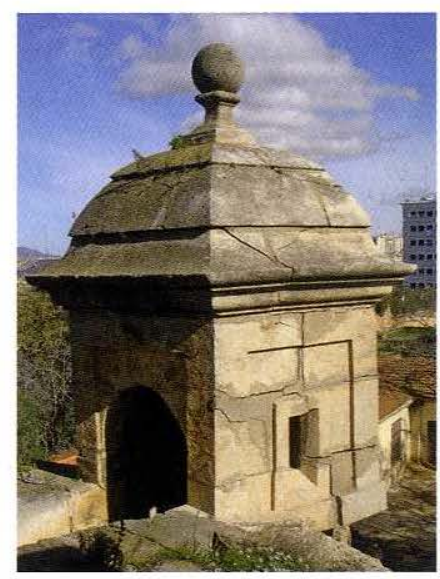

21. Echauguette au Rozalcasar.

\section{- Le fort de San Fernando:}

Situé à $250 \mathrm{~m}$ environ de Saint Philipe, auquel il est relié par un tunnel, il a pour principale fonction la défense de la source de Ras el Ain, avec le soutien, de la 
tour Nasciemento, située de l'autre côté du ravin, et comme són nom l'indique, était chargée de la défense de la source qui se trouve à ses pieds. La tour, disparue depuis, était d'une hauteur de $13 \mathrm{~m}$, couverte d'une voûte sphérique, qu'on rejoint à l'aide d'un escalier volant.

\section{2-2 Un chapelet de fortins}

Tout autour des châteaux forts, on retrouve un chapelet de fortins et autres réduits. Miguel.

En poste avancé par rapport au Rosalcazar, fut érigé Sainte Therese et saint

Santa Barbara fait la jonction entre le Rosalcazar et Saint André, lui-même disposant de San Luis en poste avancé, comme San Carlos pour le Saint Felipe. Le fortin de San Fernando ferme au sud le ravin de Ras el Aïn, appuyé sur l'autre rive par la tour de Nascienmento.

La couronne des fortins continue sur le versant est de la montagne du Murdjajo, avec le fort de San Pedro et Santiago et est fermée par le fortin de la Mona.

\section{2-3 La fortification citadelle dite : Castillo Viejo ou Casbah (Figs. 22-23):}

C'est la Casbah, arabo musulmane, la cité originelle.

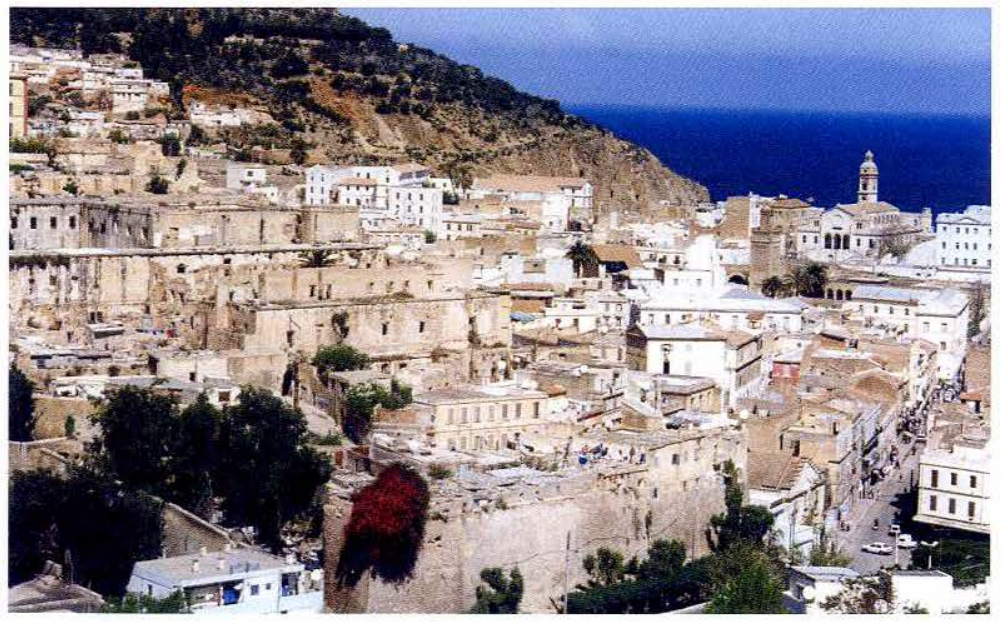


Dès la prise d'Oran, les espagnols s'attelèrent à la transformer et à la réaménager pour servir de résidence au gouverneur et de principale fortification.

Une inscription au dessus de la porte principale donne 1589 comme date de sa «construction», attribuée à don Padilla.

La configuration définitive de la fortification se présente comme un large triangle de cinq $\mathrm{Ha}$. avec, au nord, une haute et double muraille, au nord ouest un large bastion avec double tenaille;

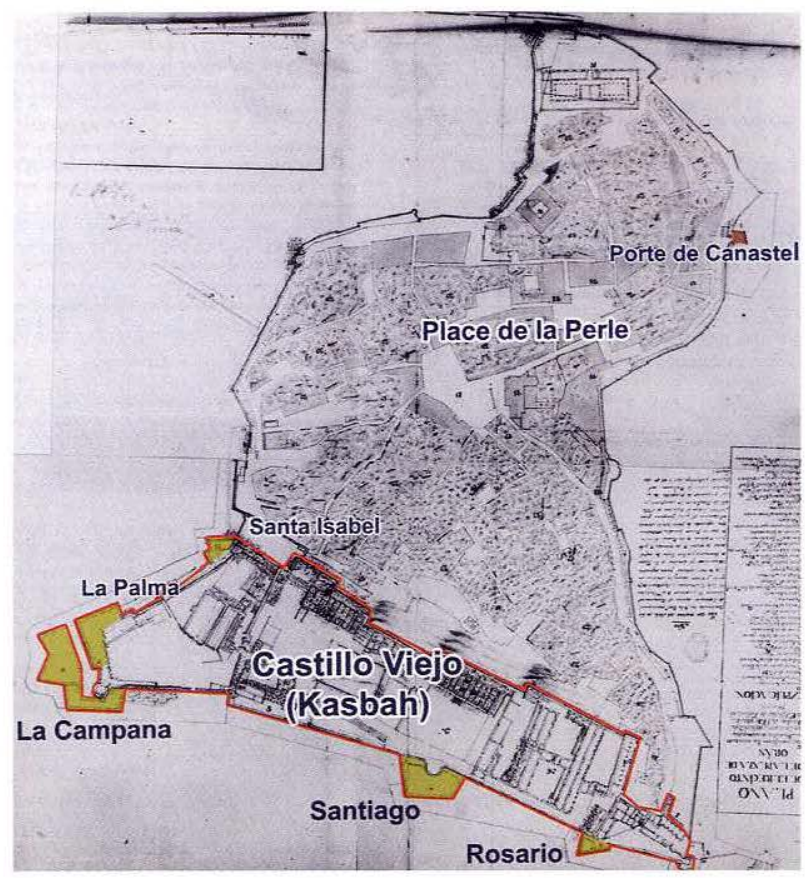

23. Plan 1732 Casbah. La longue muraille sud est judicieusement bastionnée. On retrouve d'est en ouest: les Bastion de Rosario, de Santiago, surplombé par la tour de la Campana et fermé par une double tenaille, érigée après un profond fossé (Fig. 24).

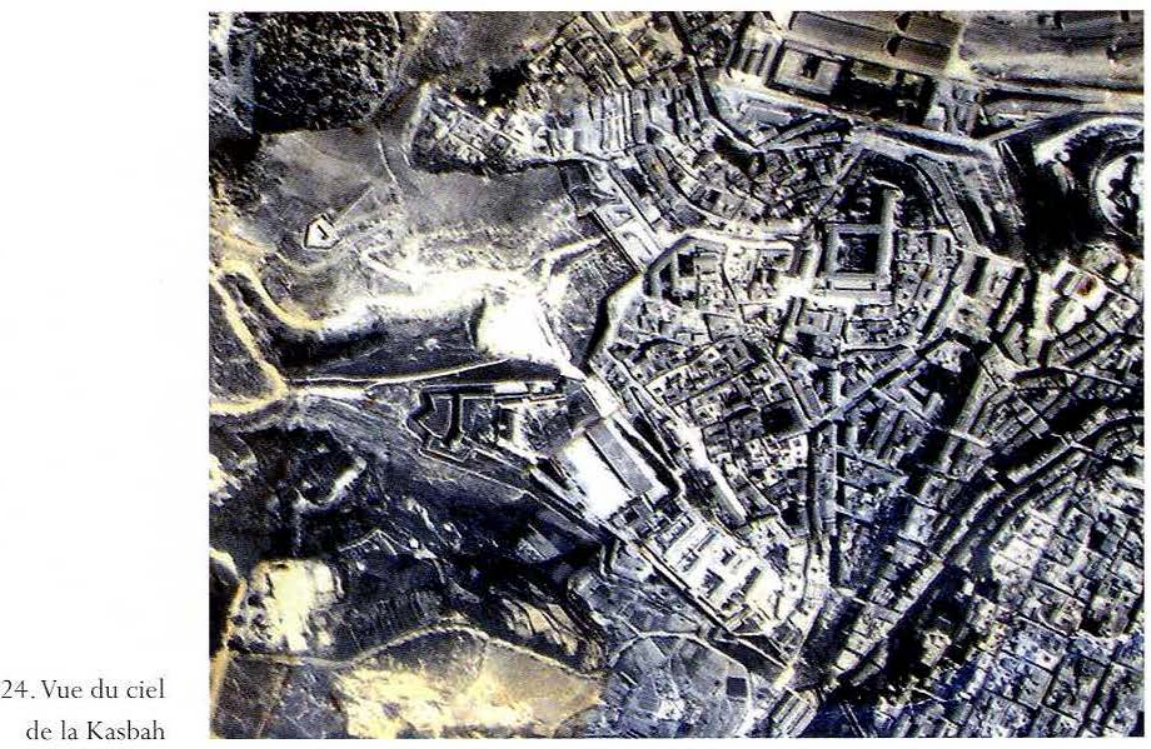


A l'est, la porte de Tlemcen donne sur une voûte portant un grand écusson, le plus beau et le plus riche d'Oran; où sont représentés les écussons et armoiries de Charles Quint, de Castille et Léon, des Deux Siciles, de la Bourgogne, de la Flandre etc.

Ce n'est pas l'unique relique que conserve encore la fortification, une carte de 1732 décrit minutieusement les diverses annexes, résidences, prisons etc.

Actuellement en état d'abandon, après avoir été squattée durant une dizaine d'année, le Castillo Viejo attend un projet de restauration et une destination Figs. 2526).

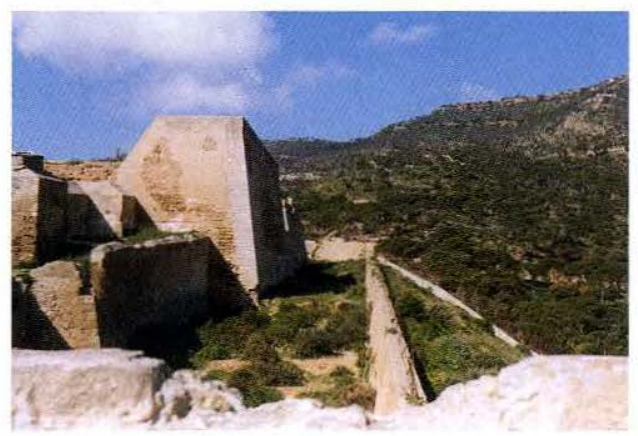

25. Bastion au CastilloViejo.

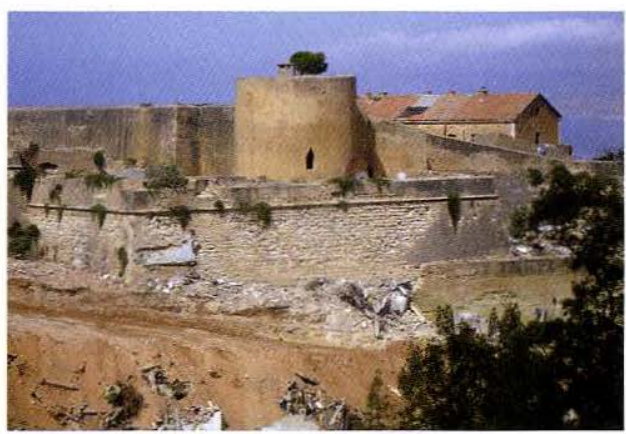

26. La double muraille du Castillo Viejo.

\section{2-4 Les galeries souterraines}

La plupart des fortifications étaient reliées entre elles, à travers des mines et galeries souterraines dont la hauteur variait de 2 mètres à un demi mètre. L'entrée principale se situait au fond du ravin, à travers le tambour San José (Fig. 27), construction en forte maçonnerie, de laquelle partait et arrivait le circuit des communications souterraines. Une carte espagnole

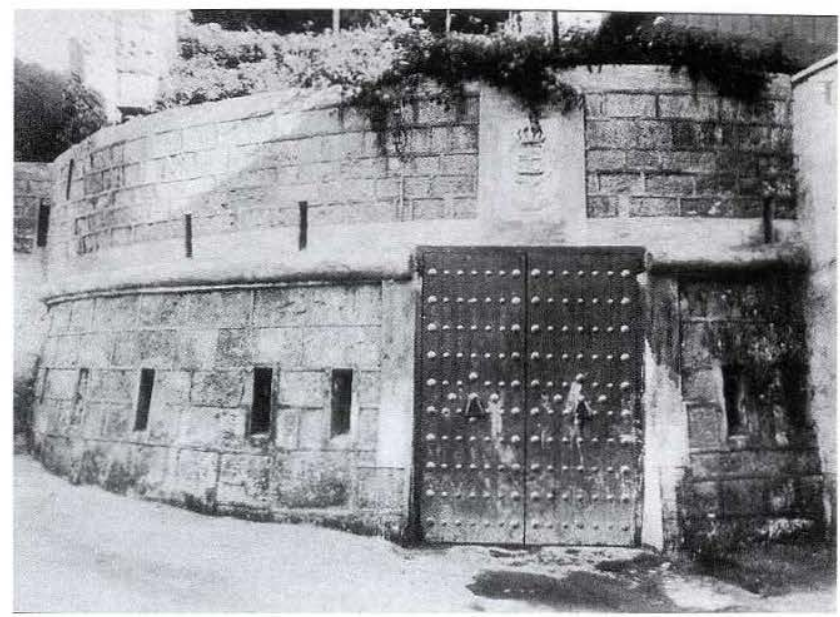

27. Le Tambour de San José. 


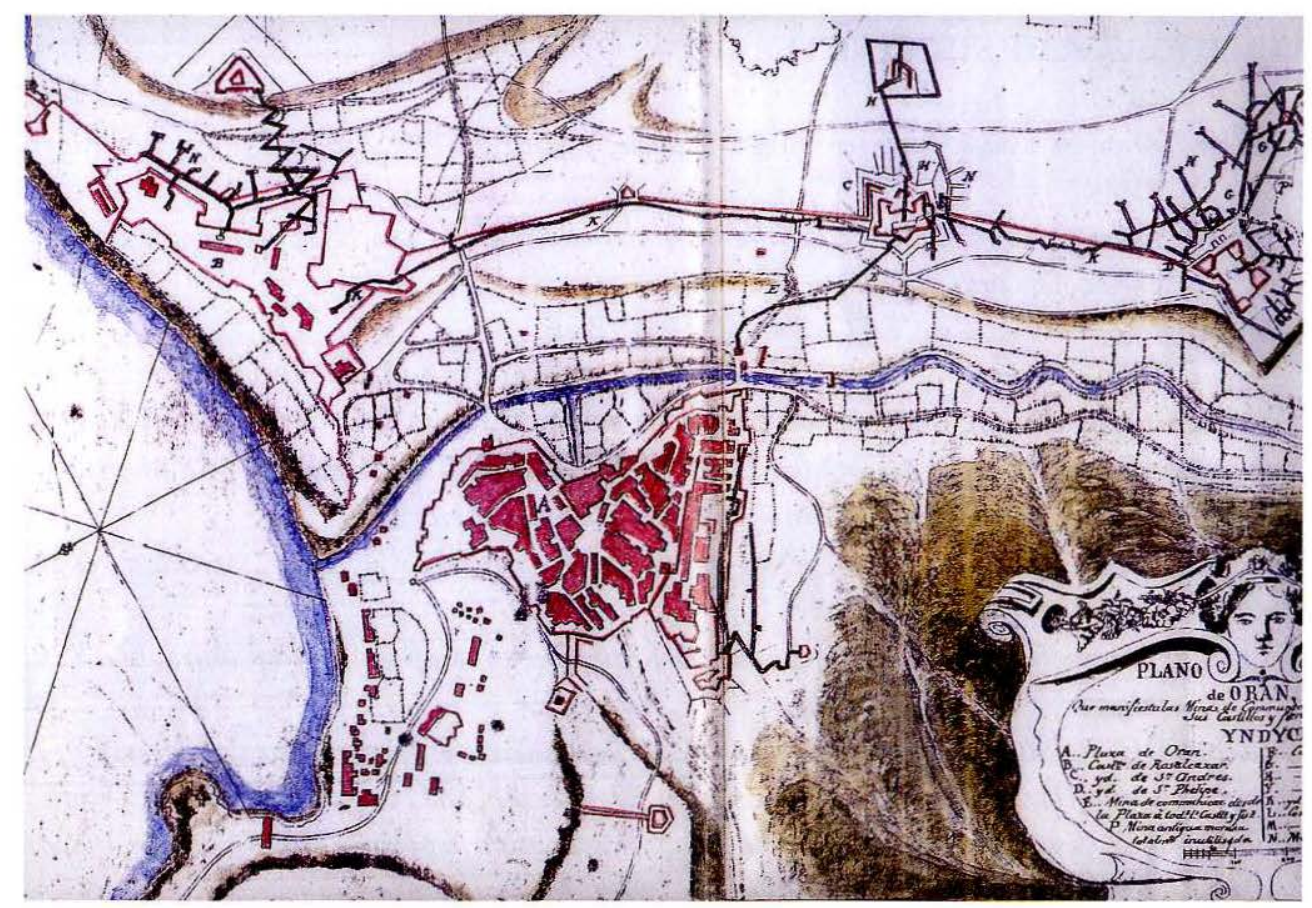

28. Plan des galeries soouterraines.

établie le tracé de ces galeries dont certaines sont encore visibles et fonctionnelles (Fig. 28).

\section{EN CONCLUSION}

Les fortifications oranaises, malgré leur importance, restent méconnus du grand public et même des spécialistes. Pour preuve aucune étude ou recherche approfondie n'a été mené depuis de longues années. A la veille du départ définitive des espagnols de la ville d'Oran, la place disposait de plus de 200 pièces d'artillerie de différentes natures et calibres et d'une trentaine de fortifications et tours bastionnées. Beaucoup de forts ont été ruinés et désarmés durant la période ottomane de 1792 à 1830. L'armée française qui prit la ville en 1831, va restaurer certains forts comme Santa Cruz, réaménager Saint Philipe et Rosalcazar et raser la plupart des fortins, murailles et bastions pour cause d'expansion urbaine. Il n'en demeure pas moins de beaux restes de ce fleuron de l'architecture militaire de l'époque avec des empreintes ottomanes, espagnoles et françaises. Un patrimoine partagé à préserver et à faire connaître. 


\section{BIBLIOGRAPHIE SUCCINCTE}

Aramburu, Oran et l'ouest algérien au $18^{\text {ime }}$ siècle, traduction El Korso et Epalza, BN, Alger, 1978

Basset R. : Fastes chronologiques de la ville d'Oran, bulletin de la société de géographie et d'archéologie, Oran, 1892

Camus A, Noces suivi de d'été, Ed Gallimard, 1959, Parsi.

Cazenave J, Pedro Navaro

Didier L, Histoire d'Oran, TV, Ed Petit 1932

Epalza M et Vilar J, Places et cartes hispaniques de l'Algérie XVI-XVIII siècle, 1988 Madrid Lespes R, Etudes de géographie et d'histoire urbaines, Réed. Bel Horizon, 2003

Fey H, Oran avant, pendant et après l'occupation espagnole, 1858 et Réed. Dar Gharb, Oran, 2002

Gorguos A, Une notice sur le Bey Mohamed el Kébir, in Revue africaine, Imp Jourdain 1859, Alger,

Hontabat DH, Relation general de la consistia de las plazas de Oran et mazalquivivir, 1772, traduction des capitaines Cassaigne et Loqueyssie, 1851, Imp Foucque 1924, Oran.

Kehl C, Santa Cruz, et Oran et l'Oranie avant l'occupation espagnole, Réed par par Lacour 1996

Pestemaldjouglou A, Ce qui subsiste de l'Oran espagnol, Revue africaine $n^{\circ} 368-369,1936$

Valejo J, Mémoire sur l'état et la valeur des places d'Oran et de Mers el Kébir

1734, Traduit par Casenave et publié in revue africaine n ${ }^{\circ} 324-325,1925$ 